\title{
Knowledge and Awareness about Preventive Health Seeking Behavior and Acceptability of Cervical Cancer Vaccine in Urban Women in Comparison with School Students
}

\author{
Hema Divakar
}

\begin{abstract}
Background: In India, cervical cancer is the single largest killer of middle-aged women, followed by breast cancer. Though the effective screening test is available, most of the women in developing and underdeveloped countries do not have access to Pap (papanicolou) smear screening due to poor literacy and low level of awareness both early detection and screening remain a major area of concern for health care persons.
\end{abstract}

Objective: To explore knowledge and awareness about preventive health seeking behavior and acceptability of cervical cancer vaccine in urban women in comparison with school students.

Materials and methods: This was a prospective study conducted to compare the awareness between 236 urban women attending the antenatal, gynaec and postdelivery outpatients and inpatients and 132 students aged between 12 to 14 years. A questionnaire was designed to tap the information about cervix-related questions, cancer cervix awareness and also about the Pap test and HPV vaccine.

Results: Overall $29.55 \%$ and urban women $19.07 \%$ did not know about the cervix. Overall, $79.55 \%$ students and $74.15 \%$ of urban women did not know about symptomatology of cervical cancer. Overall, $34.09 \%$ of students and $38.98 \%$ of women did not know about prevention of cervical cancer. Out of the total participants, $35.61 \%$ of students and $44.07 \%$ of women knew that death will happen, if cancer cervix was not treated or controlled for a long period.

Conclusion: Attempts to educate parents/peers and students themselves would intensify the awareness and improve the usage of the HPV vaccines in the desired cohort.

Keywords: Pap test, HPV vaccination, Awareness, Sociodemographic parameters, Screening.

How to cite this article: Divakar H. Knowledge and Awareness about Preventive Health Seeking Behavior and Acceptability of Cervical Cancer Vaccine in Urban Women in Comparison with School Students. J South Asian Feder Obst Gynae 2012;4(1): 47-53.

\section{Source of support: Nil}

Conflict of interest: None declared

\section{BACKGROUND}

Cervical cancer is the second most common cancer among women and is the primary cause of cancer-related deaths in developing countries. ${ }^{1}$ It is a global health problem, every year around 500,000 women develop cervical cancer and almost 280,000 of them die from the disease. ${ }^{2}$ Globally, it is the second most common cancer and $80 \%$ of these cases occurring in developing and undeveloped countries. ${ }^{3}$

In India, cervical cancer is the single largest killer of middleaged women, followed by breast cancer. The incidence of cervical cancer in Indian women population varies between 30.0 and $44.9 .^{2}$ In India more than 100,000 new cases are detected every year causing $20 \%$ of female deaths. ${ }^{4}$ Studies have shown that human papillomavirus (HPV) infection is responsible for more than $90 \%$ of the cases of invasive cervical cancer worldwide, and it is related to $80 \%$ of precancerous changes in the cervix. ${ }^{5}$ Cervical cancer can be prevented by early diagnosis and treatment. Population-based screening program utilizing exfoliative cervical cytology, the papanicolaou (Pap) test has reduced the cervical cancer morbidity and mortality in developed countries. ${ }^{6,7}$ Screening test for cervical infection of HPV, the primary cause of cervix cancer, has proved to be more effective. ${ }^{8}$ Two vaccines had been developed in recent years to prevent cervical cancer caused by HPV-16 and HPV-18. Both vaccines gave $100 \%$ efficacy in women who were not infected by HPV-16 and 18 but they are only prophylactic and do not protect against all oncogenic HPV. ${ }^{9}$

Though the effective screening test is available, most of the women in developing and underdeveloped countries do not have access to Pap smear screening. In India, due to poor literacy and low level of awareness both early detection and screening remains a major area of concern for health care persons. This ultimately becomes a barrier toward formulation of a comprehensive policy to tackle the risk of cervical cancer.

The success and benefit of a public health program depends on the awareness of the potential beneficiaries about different basic aspects of the disease. Various studies tried to assess women's awareness and knowledge level about cervical cancer. ${ }^{10-13}$ However, very less information is available on knowledge base of the Indian women on cancer of the uterine cervix.

The aim of this study was to explore knowledge and awareness about preventive health seeking behavior and acceptability of cervical cancer vaccine in urban women in comparison with school students. Additionally, we attempted to identify and analyze a probable relationship between the overall knowledge level and a few sociodemographic parameters.

The outcome measurement of this short study may provide inputs toward designing suitable information, education and communication (IEC) strategies to inform and educate the women on prevention of cervical cancer and thus augment the national cancer control program. 


\section{MATERIALS AND METHODS}

This was a prospective study conducted to compare the awareness among 236 urban women attending the antenatal, gynaec and postdelivery outpatients and inpatients and 132 students aged between 12 to 14 years. A questionnaire was designed to tap the information about cervix related questions, cancer cervix awareness and also about the Pap test and HPV vaccine. The study intended to check whether they would want to receive the vaccine and also to check the attitude on preventive health care.

\section{RESULTS}

The data of women and students was collected and compared and was analyzed, the outcome was as follows:

\section{Awareness about Cervical Cancer}

Knowledge levels of urban women and students about the cervical cancer are presented in Table 1. Overall 29.55\% and urban women $19.07 \%$ did not know about the cervix. Most of the students (70.45\%) and $59.75 \%$ of women were aware about the occurrence of cervical cancer. However, the level of awareness about the multiple sexual partners as a risk factor for cancer cervix was less known in students $(19.70 \%)$ than urban women (26.27\%). Both students $(36.36 \%)$ and women $(35.17 \%)$ were equally aware about the occurrence of cervical cancer by infection. The knowledge levels about the type of women getting cancer were poor in students $(21.97 \%)$ compare to urban woman (50\%).

\section{Awareness about Symptoms of Cervical Cancer}

The details of knowledge levels about symptoms and diagnosis of cervical cancer are presented in Table 2. Overall, 79.55\% students and $74.15 \%$ of urban women did not know about symptomatology of cervical cancer. Only $22 \%$ in both groups know the age of occurrence of cervical cancer. About $42.42 \%$ of students and $51.27 \%$ of urban women knew about Pap test and said it would detect cancer. Only $12.88 \%$ of students and $15.25 \%$ of urban women were aware prevention of cervical cancer by vaccination.

\section{Awareness about Vaccination}

Knowledge about the vaccination and other preventive measures of students and women is presented in Table 3. Overall, $34.09 \%$ of students and $38.98 \%$ of women did not know about prevention of cervical cancer. Most of the students $(61.36 \%)$ and urban women (52.97\%) were not aware of the importance of Pap smear test for periodical investigation of cervical cancer. Largest proportion of students $(61.36 \%)$ and of women $(52.97 \%)$ did know the recommended age group for vaccination.

\section{DISCUSSION}

The data focuses on the importance of Indian population to know the seriousness, consequences and the sequel of cancer cervix.

From the results, only $59.75 \%$ of women were aware about the occurrence of cervical cancer compare to students $(70.45 \%)$. Respondents (students, 37.88\% and women, $34.32 \%$ ) also believed that improper personal hygiene was a factor for cervical cancer development (Fig. 1). These referred to keeping the vaginal area clean, proper hygiene especially during menstruation and washing away the partner's semen after sexual intercourse. Poor knowledge and awareness of cervical cancer among women of different demographic and other characteristics has been reported from many countries. ${ }^{11,13-15}$ The level of awareness about the risk factors for cancer cervix was less in students and urban women; smoking (1.52 vs 9.32\%) and multiple sex partners (19.70 vs $26.27 \%$ ). From the earlier studies, 13,15 and $29 \%$ respectively could identify early onset of sexual intercourse, parity and cigarette smoking as risk factors of cervical cancer. ${ }^{16}$ Low knowledge levels of public on etiologic involvement of STIs and HPV in cervical cancer was reported from earlier Asian studies. ${ }^{17,18}$ Malaysian women aged 21 to 56 years could not identify any of these risk factors ${ }^{15}$ and the college students in Ghana had very low (1\%) awareness of the link between smoking and cervical cancer. ${ }^{14}$

Many students $(79.55 \%)$ and urban women $(74.15 \%)$ did not know about symptomatology of cervical cancer. Very few

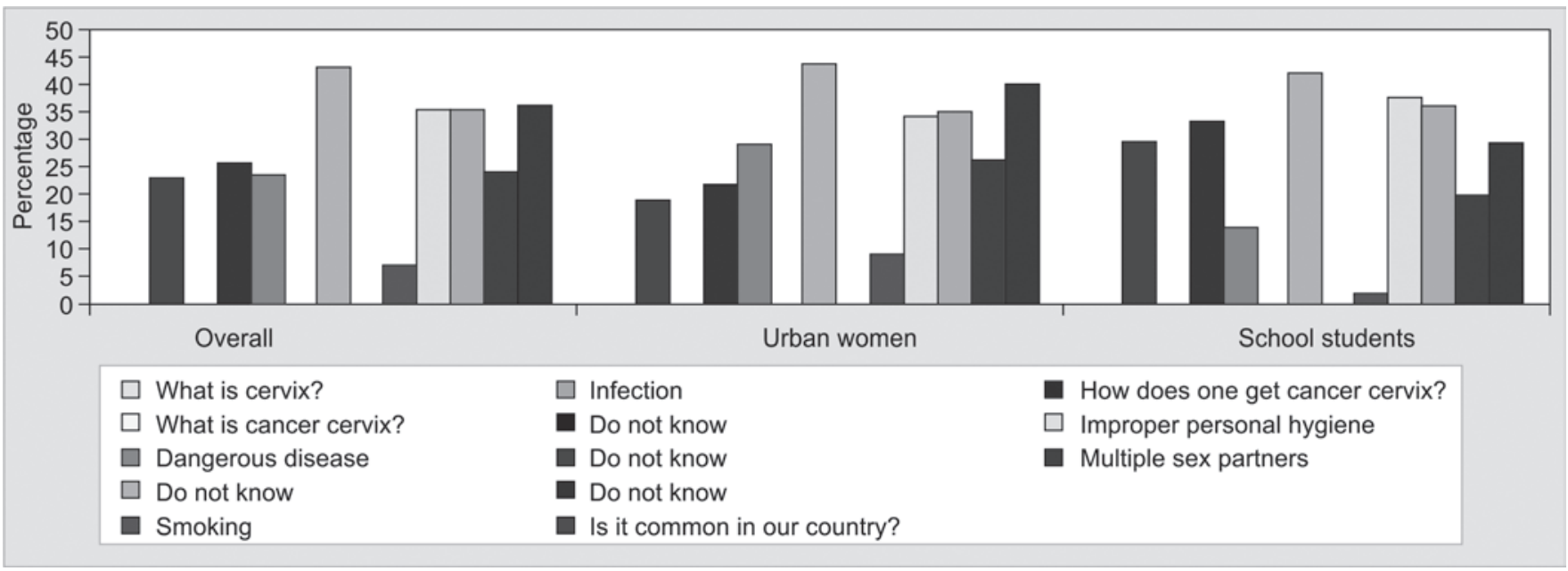

Fig. 1: Knowledge about cervical cancer 


\begin{tabular}{|c|c|c|c|c|c|c|}
\hline Characteristics & Overall & $\%$ & Urban & $\%$ & School & $\%$ \\
\hline \multicolumn{7}{|l|}{ What is cervix? } \\
\hline Mouth of uterus & 252 & 68.48 & 171 & 72.46 & 81 & 61.36 \\
\hline Part in the abdomen & 17 & 4.62 & 11 & 4.66 & 6 & 4.55 \\
\hline Do not know & 84 & 22.83 & 45 & 19.07 & 39 & 29.55 \\
\hline Uterus & 14 & 3.80 & 8 & 3.39 & 6 & 4.55 \\
\hline \multicolumn{7}{|l|}{ What is cancer cervix? } \\
\hline Infection of the cervix & 180 & 48.91 & 114 & 48.31 & 66 & 50.00 \\
\hline Do not know & 95 & 25.82 & 51 & 21.61 & 44 & 33.33 \\
\hline Ordinary disease & 4 & 1.09 & 0 & 0.00 & 4 & 3.03 \\
\hline Dangerous disease & 87 & 23.64 & 69 & 29.24 & 18 & 13.64 \\
\hline \multicolumn{7}{|c|}{ Is cancer cervix same as cancer uterus? } \\
\hline Do not know & 163 & 44.29 & 102 & 43.22 & 61 & 46.21 \\
\hline Yes & 49 & 13.32 & 27 & 11.44 & 22 & 16.67 \\
\hline No & 155 & 42.12 & 106 & 44.92 & 49 & 37.12 \\
\hline \multicolumn{7}{|c|}{ Is it common in our country? } \\
\hline Do not know & 160 & 43.48 & 104 & 44.07 & 56 & 42.42 \\
\hline Yes & 168 & 45.65 & 107 & 45.34 & 61 & 46.21 \\
\hline No & 39 & 10.60 & 24 & 10.17 & 15 & 11.36 \\
\hline \multicolumn{7}{|c|}{ How does one get cancer cervix? } \\
\hline \multicolumn{7}{|l|}{ Early marriage } \\
\hline Yes & 12 & 3.26 & 10 & 4.24 & 2 & 1.52 \\
\hline No & 356 & 96.74 & 226 & 95.76 & 130 & 98.48 \\
\hline \multicolumn{7}{|l|}{ Smoking } \\
\hline Yes & 24 & 6.52 & 22 & 9.32 & 2 & 1.52 \\
\hline No & 344 & 93.48 & 214 & 90.68 & 130 & 98.48 \\
\hline \multicolumn{7}{|l|}{ Improper personal hygiene } \\
\hline Yes & 131 & 35.60 & 81 & 34.32 & 50 & 37.88 \\
\hline No & 237 & 64.40 & 155 & 65.68 & 82 & 62.12 \\
\hline \multicolumn{7}{|l|}{ Hereditary } \\
\hline Yes & 19 & 5.16 & 9 & 3.81 & 10 & 7.58 \\
\hline No & 349 & 94.84 & 227 & 96.19 & 122 & 92.42 \\
\hline \multicolumn{7}{|l|}{ Infection } \\
\hline Yes & 131 & 35.60 & 83 & 35.17 & 48 & 36.36 \\
\hline No & 237 & 64.40 & 153 & 64.83 & 84 & 63.64 \\
\hline \multicolumn{7}{|l|}{ Multiple sex partners } \\
\hline Yes & 88 & 23.91 & 62 & 26.27 & 26 & 19.70 \\
\hline No & 280 & 76.09 & 174 & 73.73 & 106 & 80.30 \\
\hline \multicolumn{7}{|l|}{ Do not know } \\
\hline Yes & 134 & 36.41 & 95 & 40.25 & 39 & 29.55 \\
\hline No & 234 & 63.59 & 141 & 59.75 & 93 & 70.45 \\
\hline \multicolumn{7}{|c|}{ Cancer cervix occurs in which type of women? } \\
\hline \multicolumn{7}{|l|}{ Rich } \\
\hline Yes & 12 & 3.26 & 4 & 1.69 & 8 & 6.06 \\
\hline No & 356 & 96.74 & 230 & 97.46 & 126 & 95.45 \\
\hline \multicolumn{7}{|l|}{ Poor } \\
\hline Yes & 32 & 8.70 & 17 & 7.20 & 15 & 11.36 \\
\hline No & 336 & 91.30 & 230 & 97.46 & 106 & 80.30 \\
\hline \multicolumn{7}{|l|}{ House wife } \\
\hline Yes & 53 & 14.40 & 33 & 13.98 & 20 & 15.15 \\
\hline No & 315 & 85.60 & 203 & 86.02 & 112 & 84.85 \\
\hline \multicolumn{7}{|l|}{ Sex worker } \\
\hline Yes & 154 & 41.85 & 88 & 37.29 & 66 & 50.00 \\
\hline No & 214 & 58.15 & 148 & 62.71 & 66 & 50.00 \\
\hline Any woman & & & & & & \\
\hline Yes & 147 & 39.95 & 118 & 50.00 & 29 & 21.97 \\
\hline No & 227 & 61.68 & 116 & 49.15 & 111 & 84.09 \\
\hline
\end{tabular}


Table 2: Symptoms and diagnosis

\begin{tabular}{|c|c|c|c|c|c|c|}
\hline Characteristics & Overall & $\%$ & Urban & $\%$ & School & $\%$ \\
\hline \multicolumn{7}{|c|}{ A patient with cancer cervix may have } \\
\hline \multicolumn{7}{|l|}{ No symptoms } \\
\hline Yes & 28 & 7.61 & 13 & 5.51 & 15 & 11.36 \\
\hline No & 340 & 92.39 & 223 & 94.49 & 117 & 88.64 \\
\hline \multicolumn{7}{|l|}{ Profuse bleeding } \\
\hline Yes & 88 & 23.91 & 61 & 25.85 & 27 & 20.45 \\
\hline No & 280 & 76.09 & 175 & 74.15 & 105 & 79.55 \\
\hline \multicolumn{7}{|l|}{ Kidney problems } \\
\hline Yes & 1 & 0.27 & 0 & 0.00 & 1 & 0.76 \\
\hline No & 367 & 99.73 & 236 & 100.00 & 131 & 99.24 \\
\hline \multicolumn{7}{|c|}{ Which age group is likely to get cancer cervix? } \\
\hline Any age group & 116 & 31.52 & 82 & 34.75 & 34 & 25.76 \\
\hline Do not know & 140 & 38.04 & 81 & 34.32 & 59 & 44.70 \\
\hline Menopause & 29 & 7.88 & 19 & 8.05 & 10 & 7.58 \\
\hline Reproductive age group & 82 & 22.28 & 53 & 22.46 & 29 & 21.97 \\
\hline \multicolumn{7}{|l|}{ How is cancer cervix detected? } \\
\hline \multicolumn{7}{|l|}{ Blood test } \\
\hline Yes & 99 & 26.90 & 56 & 23.73 & 43 & 32.58 \\
\hline No & 269 & 73.10 & 180 & 76.27 & 89 & 67.42 \\
\hline \multicolumn{7}{|l|}{ Pap test } \\
\hline Yes & 177 & 48.10 & 121 & 51.27 & 56 & 42.42 \\
\hline No & 191 & 51.90 & 115 & 48.73 & 76 & 57.58 \\
\hline \multicolumn{7}{|l|}{ Scanning } \\
\hline Yes & 86 & 23.37 & 62 & 26.27 & 24 & 18.18 \\
\hline No & 282 & 76.63 & 174 & 73.73 & 108 & 81.82 \\
\hline \multicolumn{7}{|l|}{ HPV testing } \\
\hline \multicolumn{7}{|l|}{ Yes } \\
\hline No & 368 & 100.00 & 236 & 100.00 & 132 & 100.00 \\
\hline \multicolumn{7}{|l|}{ Can not be detected } \\
\hline Yes & 15 & 4.08 & 6 & 2.54 & 9 & 6.82 \\
\hline No & 353 & 95.92 & 230 & 97.46 & 123 & 93.18 \\
\hline \multicolumn{7}{|c|}{ Can cancer cervix be prevented? } \\
\hline Do not know & 135 & 36.68 & 80 & 33.90 & 55 & 41.67 \\
\hline Yes & 226 & 61.41 & 153 & 64.83 & 73 & 55.30 \\
\hline No & 6 & 1.63 & 2 & 0.85 & 4 & 3.03 \\
\hline \multicolumn{7}{|c|}{ Can cancer cervix be cured fully? } \\
\hline Only be controlled & 74 & 20.11 & 38 & 16.10 & 36 & 27.27 \\
\hline Do not know & 185 & 50.27 & 124 & 52.54 & 61 & 46.21 \\
\hline Yes & 101 & 27.45 & 71 & 30.08 & 30 & 22.73 \\
\hline No & 7 & 1.90 & 2 & 0.85 & 5 & 3.79 \\
\hline \multicolumn{7}{|c|}{ If yes to above question, how can it be prevented? } \\
\hline \multicolumn{7}{|l|}{ Vaccine } \\
\hline Yes & 53 & 14.40 & 36 & 15.25 & 17 & 12.88 \\
\hline No & 315 & 85.60 & 200 & 84.75 & 115 & 87.12 \\
\hline \multicolumn{7}{|l|}{ Pap smear } \\
\hline Yes & 16 & 4.35 & 7 & 2.97 & 9 & 6.82 \\
\hline No & 352 & 95.65 & 229 & 97.03 & 123 & 93.18 \\
\hline \multicolumn{7}{|l|}{ Safe sex } \\
\hline Yes & 13 & 3.53 & 10 & 4.24 & 3 & 2.27 \\
\hline No & 355 & 96.47 & 226 & 95.76 & 129 & 97.73 \\
\hline \multicolumn{7}{|l|}{ Do not know } \\
\hline Yes & 25 & 6.79 & 24 & 10.17 & 1 & 0.76 \\
\hline No & 343 & 93.21 & 212 & 89.83 & 131 & 99.24 \\
\hline
\end{tabular}




\begin{tabular}{|c|c|c|c|c|c|c|}
\hline Characteristics & Overall & $\%$ & Urban & $\%$ & School & $\%$ \\
\hline \multicolumn{7}{|c|}{$\begin{array}{l}\text { What do you think one should do to keep cancer } \\
\text { cervix under control? }\end{array}$} \\
\hline \multicolumn{7}{|l|}{ Oral drugs } \\
\hline Yes & 6 & 1.63 & 6 & 2.54 & 0 & 0.00 \\
\hline No & 362 & 98.37 & 230 & 97.46 & 132 & 100.00 \\
\hline \multicolumn{7}{|l|}{ Alternate medicines (herbs) } \\
\hline Yes & 4 & 1.09 & 1 & 0.42 & 3 & 2.27 \\
\hline No & 364 & 98.91 & 235 & 99.58 & 129 & 97.73 \\
\hline \multicolumn{7}{|l|}{ Exercise } \\
\hline Yes & 10 & 2.72 & 7 & 2.97 & 3 & 2.27 \\
\hline No & 358 & 97.28 & 229 & 97.03 & 129 & 97.73 \\
\hline \multicolumn{7}{|l|}{ Doctor's advice } \\
\hline Yes & 220 & 59.78 & 139 & 58.90 & 81 & 61.36 \\
\hline No & 148 & 40.22 & 97 & 41.10 & 51 & 38.64 \\
\hline \multicolumn{7}{|l|}{ Do not know } \\
\hline Yes & 137 & 37.23 & 92 & 38.98 & 45 & 34.09 \\
\hline No & 231 & 62.77 & 144 & 61.02 & 87 & 65.91 \\
\hline \multicolumn{7}{|c|}{$\begin{array}{l}\text { Are you aware of the importance of a Pap smear } \\
\text { test which is a periodical investigation? }\end{array}$} \\
\hline Do not know & 206 & 55.98 & 125 & 52.97 & 81 & 61.36 \\
\hline Yes & 85 & 23.10 & 58 & 24.58 & 27 & 20.45 \\
\hline No & 76 & 20.65 & 52 & 22.03 & 24 & 18.18 \\
\hline \multicolumn{7}{|c|}{$\begin{array}{l}\text { What is the recommended age group for taking } \\
\text { the vaccine? }\end{array}$} \\
\hline Adolescence & 26 & 7.07 & 11 & 4.66 & 15 & 11.36 \\
\hline Any age group & 62 & 16.85 & 42 & 17.80 & 20 & 15.15 \\
\hline Do not know & 200 & 54.35 & 124 & 52.54 & 76 & 57.58 \\
\hline Menopause & 16 & 4.35 & 12 & 5.08 & 4 & 3.03 \\
\hline Reproductive age group & 63 & 17.12 & 42 & 17.80 & 21 & 15.91 \\
\hline \multicolumn{7}{|c|}{$\begin{array}{l}\text { If the doctor suggests following treatment, what } \\
\text { would be your first choice? }\end{array}$} \\
\hline Do not know & 163 & 44.29 & 98 & 41.53 & 65 & 49.24 \\
\hline Hysterectomy & 9 & 2.45 & 4 & 1.69 & 5 & 3.79 \\
\hline Oral drugs & 13 & 3.53 & 11 & 4.66 & 2 & 1.52 \\
\hline Vaccination (3 doses) & 182 & 49.46 & 122 & 51.69 & 60 & 45.45 \\
\hline \multicolumn{7}{|c|}{$\begin{array}{l}\text { What happens, if cancer cervix is not treated or } \\
\text { controlled over a long period of time? }\end{array}$} \\
\hline \multicolumn{7}{|l|}{ Kidney problems } \\
\hline Yes & 4 & 1.09 & 1 & 0.42 & 3 & 2.27 \\
\hline No & 364 & 98.91 & 235 & 99.58 & 129 & 97.73 \\
\hline \multicolumn{7}{|c|}{ No child bearing potential anymore } \\
\hline Yes & 37 & 10.05 & 27 & 11.44 & 10 & 7.58 \\
\hline No & 331 & 89.95 & 209 & 88.56 & 122 & 92.42 \\
\hline \multicolumn{7}{|l|}{ Death } \\
\hline Yes & 151 & 41.03 & 104 & 44.07 & 47 & 35.61 \\
\hline No & 217 & 58.97 & 132 & 55.93 & 85 & 64.39 \\
\hline \multicolumn{7}{|l|}{ I do not know } \\
\hline Yes & 177 & 48.10 & 105 & 44.49 & 72 & 54.55 \\
\hline No & 191 & 51.90 & 131 & 55.51 & 60 & 45.45 \\
\hline
\end{tabular}

respondents mentioned that cervical cancer was usually asymptomatic ( 5.51 vs $11.36 \%)$. Only $20.45 \%$ of students and $25.85 \%$ of women were able to correctly list other signs and symptoms of cervical cancer, such as profuse bleeding. Most women $(48.73 \%)$ and students $(57.58 \%)$ failed to realize that the Pap smear is a cervical screening procedure (Fig. 2). None, 
however, understood the concept of precancerous lesions and cervical abnormalities. Neither did they know that the Pap smear can detect abnormal or precancerous cells and that early detection of such abnormalities could be treated easily and effectively.

Only $20 \%$ in both groups were aware that cancer cervix can be prevented by vaccination indicating the need for education right across all groups if mothers have to seek vaccination for their daughters in the younger age group. As a first choice of treatment, $45.45 \%$ students and $51.69 \%$ of women accepted vaccination. Surprisingly, $57.58 \%$ students and $52.54 \%$ women do not know about the recommended age groups for vaccination. Most of the respondents were ignorant about the consequences of the untreated cervical cancer (Fig. 3). As other studies have reported, there was a generally favorable attitude toward HPV vaccines; despite the low level of knowledge about the link between HPV and cervical cancer, 91 and $88 \%$ of women would agree to receive the vaccine in surveys that found that only 15 and $38 \%{ }^{19,20}$ respectively, had heard of HPV.

Despite advent of vaccines to prevent HPV and the impact of cervical cancer deaths, the outcome of the data recommends the HPV awareness in reproductive age women especially in developing countries, like India. The study focused on only girl students of schools in standard 12 and women of the city and conclusions of the present study could not be comprehensive to the larger Indian women population or to a population outside of the schools. Nonetheless, the selection of the study population, i.e. school girls vs urban women, could be the strength of the study, as they are the educated population and the key source of information carriers.

\section{CONCLUSION}

Attempts to educate parents/peers and students themselves would intensify the awareness and improve the usage of the HPV vaccines in the desired cohort.

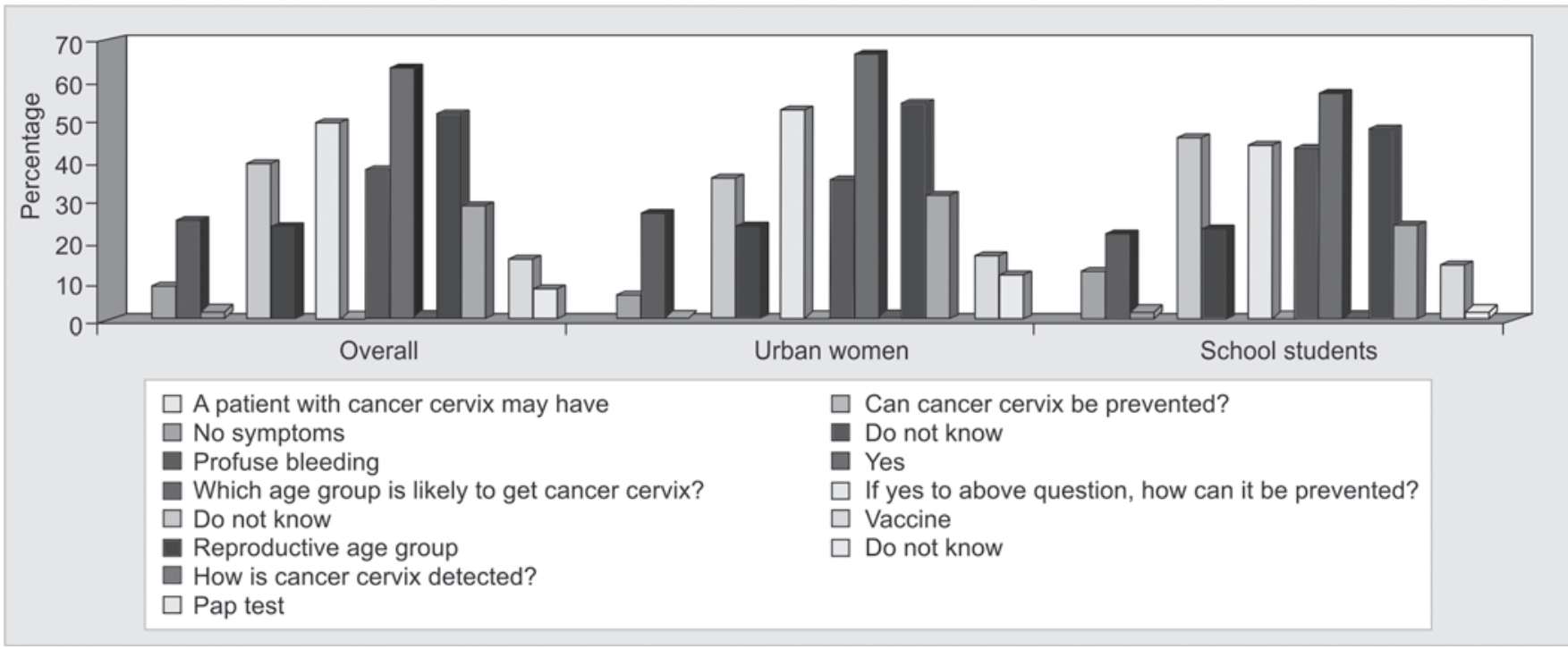

Fig. 2: Knowledge about symptoms of cervical cancer

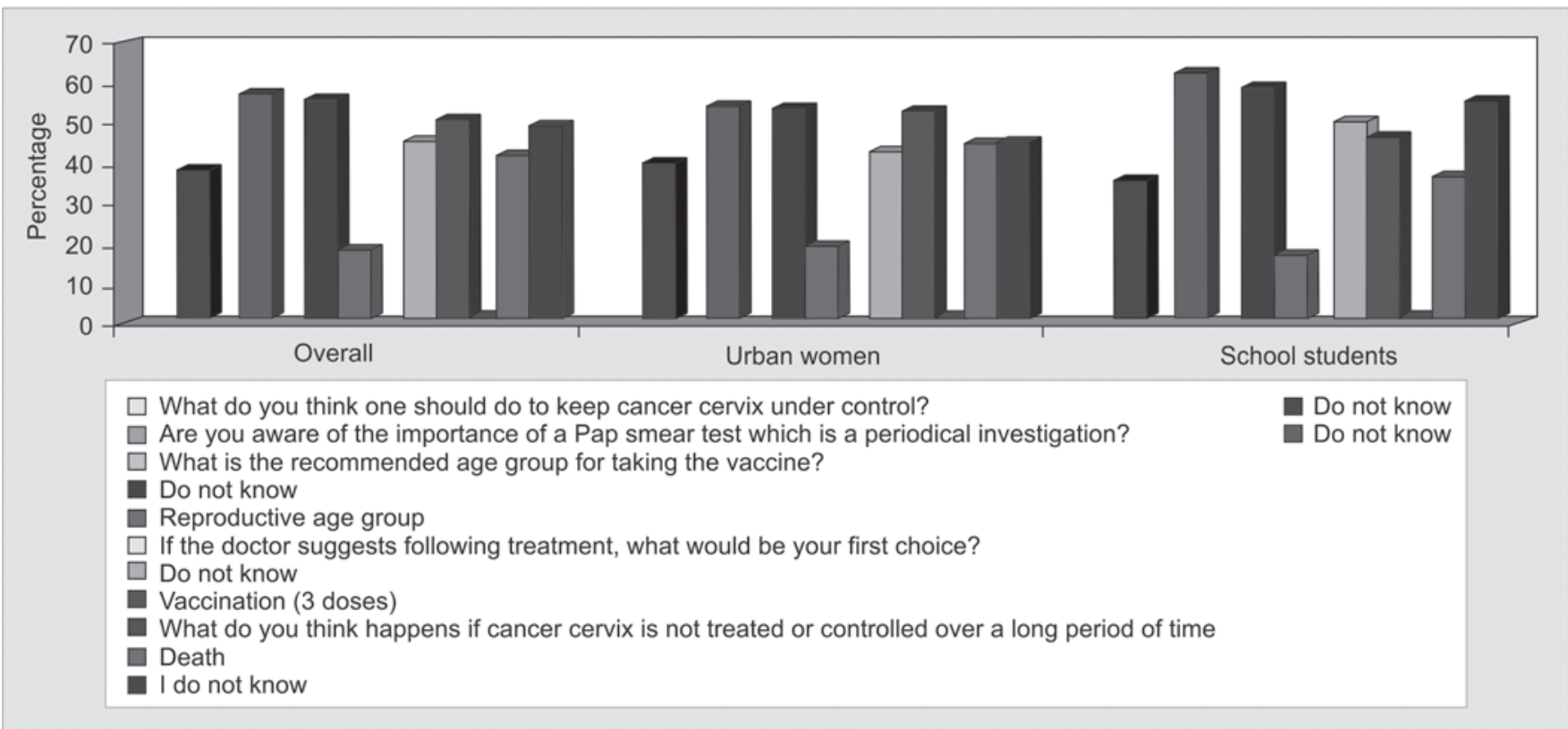

Fig. 3: Knowledge about vaccines/preventive measures 


\section{ACKNOWLEDGMENT}

We extend our sincere thanks to Dr Peter Pothula, BioQuest for his valuable editorial guidence in the generation of this report.

\section{REFERENCES}

1. Denny L. The prevention of cervical cancer in developing countries. Int J Obstet Gynaecol 2005;112:1204-12.

2. World Health Organization (WHO), PATH and the United Nations population fund (2009). Cervical cancer, human papillomavirus (HPV), and HPV vaccines: Key points for policymakers and health professionals. Geneva, CH:WHO 2007.

3. World Health Organization (WHO). Human papillomavirus infection and cervical cancer 2010.

4. Shanta V. Perspectives in cervical cancer prevention in India. The international network for cancer treatment and research 2003.

5. Walboomers JM, Jacobs MV, Manos MM, et al. Human papillomavirus is a necessary cause of invasive cancer worldwide. J Pathol 1999;189:12-19.

6. Canavan TP, Doshi NR. Cervical cancer. Am Fam Physician 2000;61:1369-76.

7. Peto J, Gilham C, Fletcher O, et al. The cervical cancer epidemic that screening has prevented in the UK. Lancet 2004;364: 249-56.

8. Free K, Roberts S, Bourne R, et al. Cancer of the cervix: Old and young, now and then. Gynecol Oncol 1991;43:129-36.

9. Kaufmann AM, Schneider A. New paradigm for prevention of cervical cancer. Eur J Obstet Gynecol Reprod Biol 2007;130: 25-29.

10. Price JH, Easton AN, Telljohann SK, et al. Perceptions of cervical cancer and pap smear screening behavior by women's sexual orientation. J Com Hlth 1996;21:89-105.

11. Ralston DJ, Taylor VM, Yasui Y, et al. Knowledge of cervical cancer risk factors among Chinese immigrants in Seattle. J Com Hlth 2003;28:41-57.
12. Sankaranarayanan R, Nene BM, Shastri SS, et al. HPV screening for cervical cancer in rural India. N Engl J Med 2009;360: 1385-94.

13. Lambert EC. College students' knowledge of human papillomavirus and effectiveness of a brief educational intervention. J Am Board Fam Prac 2001;14:178-83.

14. Peter NA, Navkiran KS. Cervical cancer screening among college students in Ghana: Knowledge and health beliefs. Int J Gynecol Cancer 2009; 19;412-16.

15. Wong LP, Wong YL, Low WY, et al. Knowledge and awareness of cervical cancer and screening among Malaysian women who have never had a Pap smear: A qualitative study. Singapore Med J 2009;50:49-53.

16. Saha A, et al. Awareness of cervical cancer among female students of premier colleges in Kolkata, India. Asian Pacific J Cancer Prev 11:1085-90.

17. Dinh TA, Rosenthal SL, Doan ED, et al. Attitudes of mothers in Da Nang, Vietnam toward a human papillomavirus vaccine. J AdolescHlth 2007;40:559-63.

18. Lee PW, Kwan TT, Tam KF, et al. Beliefs about cervical cancer and human papillomavirus (HPV) and acceptability of HPV vaccination among Chinese women in Hong Kong. Prev Med 2007;45:130-34.

19. Sauvageau C, Duval B, Gilca V, Lavoie F, Ouakki M. Human papilloma virus vaccine and cervical cancer screening acceptability among adults in Quebec, Canada. BMC Public Health 2007;7:304.

20. Kwan TT, Chan KK, Yip AM, Tam KF, Cheung AN, Lo SS et al. Acceptability of human papillomavirus vaccination among Chinese women: Concerns and implications. BJOG 2009; 116:501-10.

\section{ABOUT THE AUTHOR}

\section{Hema Divakar}

Consultant, Department of Obstetrics and Gynecology, Divakars Hospital, Bengaluru, Karnataka, India, Phone: 09900154448, e-mail: hema_divakar@yahoo.com 